\title{
RECOGNIZING ENDOGENOUS CUSHING'S SYNDROME AFTER THERAPY FOR SCLERODERMA
}

\author{
Ana Valea ${ }^{1}$, Dan Nicolae Paduraru' ${ }^{2}$ Adriana Elena Nica², Maria Iuliana Oprisor ${ }^{3}$, \\ Adina Ghemigian, ${ }^{4}$ Mara Carsote ${ }^{4}$ \\ ${ }^{1}$ Clinical County Hospital, "I. Hatieganu” University of Medicine and Pharmacy, Cluj-Napoca \\ ${ }^{2}$ University Emergency Hospital, "Carol Davila” University of Medicine and Pharmacy, Bucharest \\ ${ }^{3}$ Rehabilitation Hospital, Cluj-Napoca \\ 4 "C.I. Parhon" National Institute of Endocrinology, \\ "Carol Davila" University of Medicine and Pharmacy, Bucharest
}

\begin{abstract}
Introduction. Scleroderma induces heterogeneous skin changes due to collagen anomalies, including facial. The recommended therapy is, among others, topic cortisol derived products, so an issue of diagnosis differential regarding the etiological type of Cushing's syndrome (CS) is raised if a patient develops a suggestive phenotype.

Case presentation. This is a 64-year female presenting (since the last few months) red face, high blood pressure, central obesity. She has a 6-year history of scleroderma, intermittently treated with local corticotherapy. On admission, she associated metabolic disturbances as lipid profile anomalies, high uric acid, insulin resistance and increased number of white blood cells (which were not connected with a relapse of scleroderma, neither to an inflammatory syndrome). Low baseline plasma ACTH and morning serum cortisol level (not high, yet detectable) with abnormal diurnal rhythm suggested an adrenal source of CS. A $3 \mathrm{~cm}$ right adrenal tumor was found on computer tomography and later removed through a classical intervention. Two weeks after, the patient voluntarily reduced her prednisone dose causing an adrenal crisis which required re-admission as an emergency. After discharge, daily oral adrenal replacement therapy is needed for the moment.

Conclusions. Scleroderma, especially with skin involvement, and some of associated therapies may mask an endogenous CS as adrenal tumor derivate, thus delaying the adequate diagnosis and therapy. Patient's education regarding a potential life threatening condition as chronic adrenal insufficiency is necessary since post-operatory recovery of adrenal function is expected within 6 to 24 months.
\end{abstract}

Keywords: Cushing's syndrome, adrenal tumor, scleroderma

\author{
List of abbreviations: \\ $\mathrm{ACTH}=$ Adrenocorticotropic hormone \\ $\mathrm{CT}=$ Computed Tomography \\ $\mathrm{DXM}=$ dexamethasone \\ $\mathrm{TSH}=$ Thyroid Stimulating Hormone
}

\section{INTRODUCTION}

Cushing's syndrome displays various clinical manifestations, while rheumatologic conditions and their associated therapy may mimic it like skin changes due to scleroderma or as iatrogenic cortisol excess (1). Before specific endocrine tests are run to highlight the adequate diagnosis, a clinical index of suspicion represents the first useful step (2). We aim to present a case with adrenal Cushing' syndrome due to a right adrenal adenoma after the patient was priory treated for scleroderma. The pa- tient agreed by signing the informed consent to introduce her medical history, which includes serial hospitalization episodes in different Romanian medical centers.

\section{CASE PRESENTATION}

A 64 - year old non-smoking female, with irrelevant medical family history, was admitted for high blood pressure, weight gain (10 kilos during the last two months), with central obesity distribu- 
tion (a body mass index of $36.05 \mathrm{~kg} / \mathrm{sqm}$ ), also accusing persistent headache (Fig. 1). She developed these signs and symptoms during the last few months. Previously, she was diagnosed with scleroderma with skin involvement. She had a negative immunologic profile for nuclear antigen antibody and anti-SCL-70 antibodies but positive histology after abdominal skin biopsy confirmed the diagnosis 6 years prior. After the confirmation, she has been intermittently treated with local corticotherapy. Recently, she presented changes of face as increased redness, but from rheumatologic point of view no new anomaly was detected, neither a relapse of underlying condition. Thus, she was further referred to endocrinology considering also persistent physical changes and developing metabolic complications, which seemed unrelated to her rheumatologic disease.



FIGURE 1. Moon face and buffalo hump due to adrenal Cushing's syndrome on a 64-year old female

On admission, the patient displayed hyperuricemia, dyslipidemia, moderate white blood cells elevation (though no inflammatory syndrome was presented) and mild hypercalcemia (Table 1). Hyperinsulinemia and increased HOMA index was diagnosed, also (Table 1). Hormonal profile revealed abnormal plasma cortisol rhythm, non-suppression at dexamethasone (DXM) tests in association with low levels of ACTH (Adrenocorticotropic Hormone) (Table 1). These aspects were consistent for a potential adrenal source of hypercortisolemia. Abdominal computer tomography (CT) scan highlighted a right adrenal tumor of 30 by $30 \mathrm{~mm}$ (millimeter) (Fig. 2). Normal thyroid function was found, but thyroid ultrasound revealed a nodule of 10.5 by $8.3 \mathrm{~mm}$ located at the lower pole of the left lobe. Moreover, normal parathormone levels with relatively low levels of vitamin D did not explain accidental total (not ionic) blood calcium increase (Table 1).

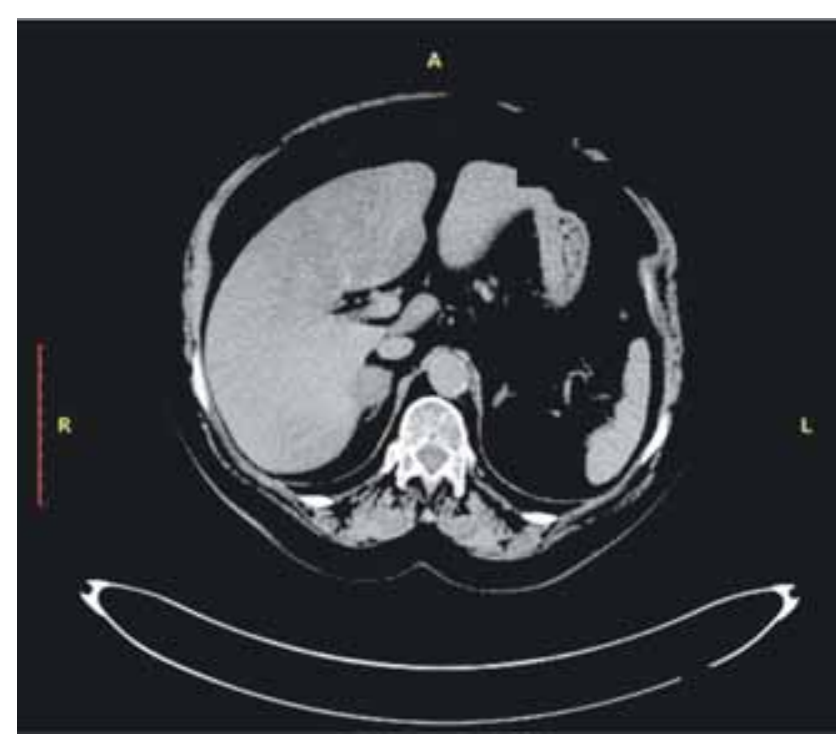

FIGURE 2. Abdominal computer tomography scans on a 64-year old patient with adrenal Cushing's disease: right adrenal solid mass of 30 by 30 millimeter (native acquisition; coronal section)

Right adrenalectomy was performed two weeks later by a classic approach due to increased abdominal fat. No complications were reported intra or post-operatively. The pathological report confirmed adrenal Cushing's syndrome. The histological pattern pointed a yellow tumor mass including pale cells proliferation with intra-cytoplasm droplets and compact cells with eosinophilic cytoplasm. The subject was hospitalized for 11 days and after discharge she continued with oral prednisone 10 $\mathrm{mg}$ (milligrams) per day. After two weeks, she voluntarily reduced prednisone dose to $5 \mathrm{mg}$ per day with progressive physical deterioration. Two weeks later she was re-admitted as an emergency in a regional intensive care unit with clinical manifestations suggestive for acute adrenal insufficiency. In addition, laboratory tests revealed low serum sodium (of $113 \mathrm{mmol} / \mathrm{L}$, normal between 136-146 $\mathrm{mmol} / \mathrm{L}$ ), hypochloremia (of $82.1 \mathrm{mmol} / \mathrm{L}$, normal levels between 101-109 mmol/L) but normal potassium and fasting blood glucose. She was hospitalized for 14 days while intravenous adrenal replacement was added, and after discharge she continued with prednisone $7.5 \mathrm{mg}$ per day and daily fludrocortisone $0.1 \mathrm{mg}$. Most recent evaluation was done three months after adrenal surgery and it revealed slightly reduced serum sodium thus an adjustment of daily fludrocortisones dose was done; also persistent high index of insulin resistance was suggestive for associated metabolic risk (Table 1). The level of blood calcium normalized while hypovitaminosis D continued to be presented and vitamin D supplements were offered to the patient. Periodic 
TABEL 1. Biochemical and hormonal profile of a 64-year old female withadrenal Cushing's syndrome: at diagnosis and three months after right adrenalectomy was done

\begin{tabular}{|c|c|c|c|}
\hline Parameter & Value & Normal limits & Units \\
\hline \multicolumn{4}{|l|}{ At diagnosis } \\
\hline Fasting blood glucose & 102 & $74-106$ & $\mathrm{mg} / \mathrm{dL}$ \\
\hline Serum sodium & 141 & $136-145$ & $\mathrm{mmol} / \mathrm{L}$ \\
\hline Serum potassium & 3.5 & $3.7-5.4$ & $\mathrm{mmol} / \mathrm{L}$ \\
\hline Total cholesterol & 299 & $<200$ & $\mathrm{mg} / \mathrm{dL}$ \\
\hline Triglycerides & 232 & $<150$ & $\mathrm{mg} / \mathrm{dL}$ \\
\hline Uric acid & 7.71 & $3-5$ & $\mathrm{mg} / \mathrm{dL}$ \\
\hline Serum total calcium & 10.81 & $8.8-10.6$ & $\mathrm{mg} / \mathrm{dL}$ \\
\hline Serum ionized calcium & 4.92 & 4.4-5.4 & $\mathrm{mg} / \mathrm{dL}$ \\
\hline Fasting plasma insulin & 54.3 & $2-28.4$ & $\mu \mathrm{U} / \mathrm{mL}$ \\
\hline HOMA INDEX & 15.68 & $2-2.5$ & \\
\hline Leucocytes & 11,680 & $4-10,000$ & $/ L$ \\
\hline Morning plasma cortisol & 16.6 & $5-25$ & $\mu \mathrm{g} / \mathrm{dL}$ \\
\hline Plasma cortisol (11 p.m.) & 14.8 & $2.5-13$ & $\mu \mathrm{g} / \mathrm{dL}$ \\
\hline $\begin{array}{l}\text { ACTH } \\
\text { (Adrenocorticotropic Hormone) }\end{array}$ & 1.35 & $7.2-63.3$ & $\mathrm{pg} / \mathrm{mL}$ \\
\hline Plasma cortisol after $1 \mathrm{mg}$ DXM overnight test & 17.2 & $<1.8$ & $\mu \mathrm{g} / \mathrm{dL}$ \\
\hline Plasma cortisol after $8 \mathrm{mg}$ DXM overnight test & 26.2 & $\begin{array}{c}<50 \% \text { of baseline plasma cortisol } \\
\text { suggestive for adrenal source }\end{array}$ & $\mu \mathrm{g} / \mathrm{dL}$ \\
\hline $\begin{array}{l}\text { TSH } \\
\text { (Thyroid Stimulating Hormone) }\end{array}$ & 1.09 & $0.4-4$ & $\mu \mathrm{IU} / \mathrm{mL}$ \\
\hline $\begin{array}{l}\text { FT4 } \\
\text { (Free Levothyroxine) }\end{array}$ & 1.10 & $0.89-1.76$ & $\mathrm{ng} / \mathrm{dL}$ \\
\hline $\begin{array}{l}\text { TPOAb } \\
\text { Thyreoperoxidase antibodies }\end{array}$ & 26.3 & $<50$ & $\mathrm{U} / \mathrm{mL}$ \\
\hline Blood calcitonin & 2.54 & $0-11.5$ & $\mathrm{ng} / \mathrm{mL}$ \\
\hline Intact parathormone & 53.1 & $11-67$ & $\mathrm{pg} / \mathrm{mL}$ \\
\hline 25-hydroxyvitamin D & 24.1 & $30-100$ & $\mathrm{ng} / \mathrm{mL}$ \\
\hline \multicolumn{4}{|l|}{3 months after surgery } \\
\hline Fasting blood glucose & 112 & $74-106$ & $\mathrm{mg} / \mathrm{dL}$ \\
\hline Serum sodium & $142^{*}$ & $136-145$ & $\mathrm{mmol} / \mathrm{L}$ \\
\hline Serum potassium & 4.6 & 3.7-5.4 & $\mathrm{mmol} / \mathrm{L}$ \\
\hline Total cholesterol & 186 & $<200$ & $\mathrm{mg} / \mathrm{dL}$ \\
\hline Triglycerides & 125 & $<150$ & $\mathrm{mg} / \mathrm{dL}$ \\
\hline Serum total Calcium & 10.03 & 8.8-10.6 & $\mathrm{mg} / \mathrm{dL}$ \\
\hline Serum ionized Calcium & 5.34 & 4.4-5.4 & $\mathrm{mg} / \mathrm{dL}$ \\
\hline Fasting plasma insulin & 37.2 & $2-28.4$ & $\mu \mathrm{U} / \mathrm{mL}$ \\
\hline HOMA INDEX & 10.28 & $2-2.5$ & \\
\hline $\begin{array}{l}\text { TSH } \\
\text { (Thyroid Stimulating Hormone) }\end{array}$ & 0.54 & $0.4-4$ & $\mathrm{ulU} / \mathrm{mL}$ \\
\hline $\begin{array}{l}\text { FT4 } \\
\text { (Free Levothyroxine) }\end{array}$ & 1.15 & $0.89-1.76$ & $\mathrm{ng} / \mathrm{dL}$ \\
\hline Intact parathormone & 67.7 & $11-67$ & $\mathrm{pg} / \mathrm{mL}$ \\
\hline 25-hydroxyvitamin D & 24.7 & $30-100$ & $\mathrm{ng} / \mathrm{mL}$ \\
\hline
\end{tabular}

*under fludrocortisone $0.1 \mathrm{mg}$ per day

thyroid assays and ultrasound is recommended, as well as periodic check-up of adrenal function recovery is needed.

\section{DISCUSSIONS}

This case represents a real life medicine presentation. The scleroderma induces heterogeneous skin changes due to collagen anomalies including facial redness, which is not typical (3). In this case, the cause was related to adrenal associated cortisol excess, not to the rheumatologic disease. The recommended therapy for scleroderma, as in this particular situation, consisted in topic cortisol derived products, which were intermittently used so an issue of differential diagnosis regarding the etiologi- 
cal type of Cushing's syndrome was raised. (4) However, the value of morning plasma ACTH and then the morning plasma cortisol level which was not high yet detectable were opposite to iatrogenic Cushing's syndrome assays $(5,6)$. The female subject associated the classical combination of hypercorticism- related metabolic disturbances as high blood pressure, obesity, lipid profile anomalies, high uric acid, insulin resistance (but not clear cut diagnosis of secondary diabetes mellitus) and increased number of white blood cells (which were not connected with a relapse of scleroderma and related inflammatory syndrome) (7). The biochemistry profile also included mildly elevation of total serum calcium, but the albumin corrected ionic level was normal. Persistent hypercortisolemia may damage the bone metabolism including hypercalciuria, bone resorption and fragility fractures, but in this presented case only a relatively reduced level of 25-hydroxyvitamin D was detected (which is controversial to be directly linked with adrenal cortisol excess) $(8,9)$. Two more aspects worth to be mentioned: the classical adrenalectomy that was done is rather on old school approach but excessive abdominal pad and previous abdominal surgery

\section{REFERENCES}

1. Kreitschmann-Andermahr I., Psaras T., Tsiogka M., et al. From first symptoms to final diagnosis of Cushing's disease: experiences of 176 patients. Eur J Endocrinol. 2015 Mar; 172(3):285-9. doi: 10.1530/ EJE-14-0766.

2. Lonser R.R., Nieman L., Oldfield E.H. Cushing's disease: pathobiology, diagnosis, and management. J Neurosurg. $2016 \mathrm{Apr}$ 22:1-14.

3. Sperber K., Ash J., Gutwein F., Wasserrman A., Rao V., Tratenberg M. Localized Scleroderma: A Clinical Review. Curr Rheumatol Rev. 2016 Sep 7. [Epub ahead of print]

4. Desbois A.C., Cacoub P. Systemic sclerosis: An update in 2016. Autoimmun Rev. 2016 May; 15(5):417-26. doi: 10.1016/j. autrev.2016.01.007.

5. Shen J., Sun M., Zhou B., Yan J. Nonconformity in the clinical practice guidelines for subclinical Cushing's syndrome: which guidelines are trustworthy? Eur J Endocrinol. 2014 Oct; 171(4):42131. doi: 10.1530/EJE-14-0345.

6. Poiana C., Chirita C., Carsote M., et al. Adrenal and pituitary incidentalomas in a case of Cushing's syndrome. Chirurgia (Bucur). 2013 Nov-Dec; 108(6):886-91. may impair a laparoscopic technique while the poor compliance showed by the patient after she was released from surgical center needs a patient's education regarding a potential life threatening condition as chronic adrenal insufficiency (which is expected for at least 6 months and for maximum two years after adrenal tumor is removed) $(10,11)$. We consider the nodular goiter as incidental, noting that the patient had normal thyroid function and autoimmune profile, probably connected to her pre-exposure to an endemic zone and less likely related to the adrenal tumor.

\section{CONCLUSIONS}

Scleroderma, especially with skin involvement, and some of associated therapies may mask an endogenous source of cortisol excess as adrenal tumor derivate thus delaying the adequate diagnosis and therapy.

Acknowledgement: we thank each member of the medical team and the patient for giving the consent for use the medical records and images below.

7. Barnett R. Cushing's syndrome. Lancet. 2016 Aug 13; 388(10045):649.

8. Muscogiuri G., Altieri B., Penna-Martinez M., Badenhoop K. Focus on vitamin D and the adrenal gland. Horm Metab Res. 2015 Apr; 47(4):239-46. doi: 10.1055/s-0034-1396893.

9. Warriner A.H., Saag K.G. Glucocorticoid-related bone changes from endogenous or exogenous glucocorticoids. Curr Opin Endocrinol Diabetes Obes. 2013 Dec; 20(6):510-6. doi: 10.1097/01. med.0000436249.84273.7b.

10. Prete A., Paragliola R.M., Bottiglieri F., et al. Factors predicting the duration of adrenal insufficiency in patients successfully treated for Cushing disease and nonmalignant primary adrenal Cushing syndrome. Endocrine. 2016 Jul 9.

11. lacobone M., Citton M., Scarpa M., et al. Systematic review of surgical treatment of subclinical Cushing's syndrome. Br J Surg. 2015 Mar; 102(4):318-30. doi: 10.1002/bjs.9742. 